\title{
Beyond Expectations: From Foster Children to Foster Parents
}

\author{
Leslie S. Hamilton ${ }^{1} \&$ Victor W. Harris ${ }^{1, *}$ \\ ${ }^{1}$ Department of Family, Youth, \& Community Sciences, University of Florida, USA \\ * Corresponding author: Department of Family, Youth, \& Community Sciences, University \\ of Florida, P.O. Box 110310, 3028 D McCarty Hall D, Gainesville, Florida 32611, USA. Tel: \\ 1-352-273-3523. E-mail: victorharris@ufl.edu
}

Received: November 15, 2017 Accepted: November 30, 2017 Published: January 5, 2018

doi:10.5296/ije.v10i1.12147ＵRL: https://doi.org/10.5296/ije.v10i1.12147

\begin{abstract}
Little research exists on long-term outcomes for adults who have been in foster care as children, with even less research on former foster children who become foster parents themselves. Foster care and maltreatment exert significant independent and interdependent impacts on youth outcomes. While traditional research often focuses on predicting and mitigating negative outcomes, new studies indicate success using a positive youth development approach that is strengths-based targeting positive outcomes, such as strong empathy skills. These outcomes align with the demonstrated skills that lead to successful foster parenting. The current review examines the possible transition from foster child to foster parent through the lenses of parenting styles, attachment, and family systems theories, as well as positive youth development and social justice youth development theories. The authors propose utilizing theory and proven interventions to address foster youths' attachment and emotional development needs, recognize positive outcomes for youth in foster care, and employ evidence-based training programs in place for at-risk parent groups to help break the cycle that leads to displacement. The need for more research to assist foster children, parents, case workers, and systems to promote healthy youth development is discussed.
\end{abstract}

Keywords: attachment, former foster youth, foster care, parenting styles, social justice youth development 


\section{Introduction}

Children in foster care are among the most vulnerable youth in our society. Placement in foster care is most often the result of one or more traumatic events, including the death of a parent or maltreatment, including abuse, neglect, abandonment, and a myriad of more harmful parenting behaviors (Bigner, 2010). These children experience intense disruption to their lives that significantly impacts their development often resulting in attachment, trust, emotional, social, psychological, and physical well-being issues. Two models of family violence, the ecological model and the social psychological model, are especially useful in understanding child maltreatment in the context of youth placed in foster care. The former, working from systems theory, posits that a child's development impacts the way a family system organizes, while the family unit then operates as a part of the larger community. Support or lack of support can determine the parents' use of maltreatment behaviors and resultant child adaptive or maladaptive actions. Further, the social psychological model argues that children learn patterns of behavior from their parents and other family members; if the parents use violence to handle conflict and stress, so will the children (Bigner, 2010).

Children often enter foster care having suffered emotional, psychological, and/or physical maltreatment along with learned maladaptive coping skills, all while experiencing disruption and loss. This combination of factors often leads to negative outcomes for youth (e.g., Bigner, 2010; Ahmed, Windsor, \& Scott, 2015; Fuentes, Salas, Bernedo, \& Garcia-Martin 2014). However, many young people who move through the foster care system experience positive outcomes and healthy development; this is especially true for those who leave dangerous situations, are placed with proactive, well-trained foster caregivers, and receive support from the wider community. Foster families represent a significant factor in ensuring the success of the children placed with them. Those who employ positive parenting techniques, develop strong attachments with the youth, and build relationships with birth families are more likely to increase positive outcomes for the children in their care (e.g. Bunday, Dallos, Morgan, \& McKenzie, 2015; Crum, 2010; Gillis-Arnold, Crase, Stockdale, \& Shelley II, 1998).

While little research has been conducted on foster children who leave the foster care system, especially longitudinal research that examines their lives as they emerge into adulthood, a lot of research exists on programs that train adults to help youth. This research includes training for adults in high-risk situations, such as homelessness (Perlman, Cowan, Gewirtz, Haskett, \& Stokes, 2012), youth in high-risk situations, such as teen motherhood (Svoboda, Shaw, Barth, \& Bright, 2012), and simple skills that help adults facilitate positive youth development in family, school, or community settings (e.g. Clary \& Rhodes, 2006; Small \& Memmo, 2004). This training could be expanded to apply evidence-based youth development programs to foster children to mitigate the negative impacts of trauma and promote positive developmental outcomes.

This article examines the question of how youth in foster care can gain the critical skills necessary to negotiate successful foster care placements as adults. The research on former foster youth who become foster parents is scarce; as a result, the authors take a theoretical approach to explore how this transition could be achieved successfully. Parenting styles, 
attachment, and family systems theories all contribute to an understanding of how youth develop positive relationships and intra/interpersonal skills, leading to positive outcomes for foster youth. Positive youth development and social justice youth development can help explain how an assets-based approach to working with young people provides opportunities for youth, family, and community growth (Benson, Galbraith, \& Espeland, 2006). Together, these concepts lay the foundation for a framework in which youth in foster care can gain the skills necessary to successfully parent foster children as adults.

\section{Literature Review}

The most significant finding in studies of youth in foster care, foster parents, and social services agencies is the overall consensus regarding a lack of adequate existing research about foster youth who become foster parents. In this section, the context surrounding this research is discussed, including potential outcomes for foster youth, characteristics of successful foster caregivers, and programs that could potentially be modified to benefit those who are associated with the foster system.

\subsection{Foster Youth and Foster Families}

While there is a dearth of research on how foster parents' parenting styles impact foster child development (Vanderfaeillie, Van Holen, Trogh, \& Andries, 2012), Ahmed et al. (2015) worked directly with youth in foster care to understand both their needs and the associated outcomes. These children experienced multiple parenting styles, from maltreatment with their biological families to a myriad of styles in their foster families. Foster youth were able to identify their needs concretely: care and security; strong relationships with their foster and birth families, if possible; positive outcomes for adulthood; and living normal teenage lives. While most youths in the study would have preferred not being in a situation necessitating their removal from their family of origin, they were largely able to reflect positively on their ability to thrive in their foster homes.

Harden, Meisch, Vick, and Pandohie-Johnson's (2008) study found that attachment to the foster child is the most significant factor in determining positive youth outcomes and foster parents' perceptions of success. With help, foster children can learn to form more secure attachments (Bunday et al., 2015). Foster parents' reflective functioning (RF) is a significant determinant of their ability to form attachments with their foster children. Reflective functioning is the ability to reflect on self, on the child's experiences, and on the connection between the two (Bunday et al., 2015). Higher RF scores mean caregivers are more capable of reaching youth and positively impacting their outcomes. When caregivers are strong on self-RF, they are more likely to help children under their care. Furthermore, recognition of mutual attachment--not using children to fulfill caregiver needs--promotes healthy development, though lower RF could mean caregivers assign their own emotions to children's behaviors (Bunday et al., 2015). In fact, "when child insecurity is met with caregiver insecurity, combined with any pre-existing vulnerability resulting from the child's prior experiences, there is an increased risk of disorganized attachment" (Bunday et al., 2015, p. 
146).

If a child is in a healthy environment, they are more likely to experience positive outcomes; however, some research demonstrates that disruption of care (e.g., placement in the foster system or movement from one foster home to another) often leads to worse externalizing behaviors (Vanderfaeillie et al., 2012). Positive outcomes are more likely when disruption, whether from the family of origin or from a foster family, means the children are moved out of dangerous situations; this is especially true when the children are removed from maltreatment and placed in homes that promote positive development. Correspondingly, Holland (2009) found that children who are placed in foster care and then age out without adoption or reunification with the birth family demonstrated worse outcomes than those who were in situations of maltreatment, but remained with their biological family, suggesting a complicated calculus of factors that influence these outcomes. A child's personal characteristics and history of maltreatment, especially sexual abuse, mediates placement disruption (Crum, 2009), yet Fuentes et al. (2014) found that traits like age, race/ethnicity, and length of placement were not significant predictors of displacement.

Foster youth recognize both positive and negative parenting styles, especially by comparing their foster and birth family environments (Ahmed et al., 2015). Certain parenting styles lead to successful placements for both foster youth and foster parents (Ahmed et al., 2015; Crum, 2009). Youth seek positive but reasonable discipline and boundaries; wish to have a voice in family decisions, especially when determining their own lives; and crave attachment, caring, trust, and support. They also see these characteristics demonstrated through words, routine attitudes, and behaviors (Ahmed et al., 2015). Placement stability is best facilitated when the foster families employ a positive, authoritative parenting style through demonstrating support and setting limits. This style is marked by creating connections with the children placed in the foster home through nurturing and responsiveness behaviors and inclusion of the children in decisions. Conversely, placement disruptions - when a child moves from one foster home to another-are more likely when foster families employ authoritarian parenting and do not take the children's opinions into account (Crum, 2009).

\subsubsection{Youths' Externalizing Behaviors}

Extensive research shows that foster children's behavior impacts the stability of their placements (Vanderfaeillie et al., 2012). Youths' externalizing behaviors are mediated by their ability to process both their family experiences and their reactions (Holland, 2009); foster caregivers who are able to help their foster children work through these difficult emotions will form more secure attachments and have more successful placements. Conversely, failure to understand why a child behaves the way they do, especially emotionally, can lead to conflict and lack of attachment between foster parents and youth (Bunday et al., 2015).

Foster parents exhibit greater parenting stress than biological parents, often related to poor externalizing behaviors from the children in their care; the parental response often entails attempts to end the problematic behaviors as quickly as possible, rather than dealing with the behaviors and the children in positive ways. Vanderfaeillie et al. (2012) demonstrated that 
parental stress did not mediate the effects of child behavior on parenting behaviors; what did impact both parenting behavior and stress, however, were problematic behaviors from the children. When youths acted out, foster parents used more negative and/or inconsistent discipline (Vanderfaeillie et al., 2012). Furthermore, poor child behavior could remind caregivers of previous trauma/problematic relationships which lead to negative outcomes (Bunday et al., 2015).

\subsubsection{Training}

Children whose foster parents underwent training showed more positive outcomes like reduced externalizing behaviors; further, these foster parents were more likely to demonstrate the necessary parenting skills to meet their children's needs for acceptance and safety, while youth whose foster parents were inadequately trained were more likely to experience disrupted placements (Crum, 2009; Solomon, Niec, \& Schoonover, 2017). Training is essential to ensure foster parents intentionally employ positive parenting techniques to deal with problematic behaviors in positive ways (Vanderfaeillie et al., 2012).

Linares et al. (2006) proposed a joint training program in which foster and biological families learn together, based on several key factors: birth families must undergo rigorous parenting education as a condition of reunification; youth outcomes are strengthened when foster parents attend effective training; and a foster child's emotional well-being is best served by foster families who acknowledge and support families of origin. Co-parenting and collaboration between biological and foster families led to longer lasting gains in positive parenting for both groups, and their children exhibited fewer externalizing behaviors than those whose parents went through more standard training (Linares, Montalto, Li, \& Oza, 2006).

Building on collaborative efforts between foster and biological families, Franks et al. (2013) studied the effects of behavioral parent training (BPT) programs on parenting skills. They retroactively examined a program working on positive parenting skills like "Avoid Coercion," "Stay Close," and "Redirect-Use Reinforcement" (Franks et al., 2013, p. 378), designed for foster parents and adapted to work with birth families who were at risk of either having their children removed from their homes for maltreatment or for falling into maltreatment behaviors. The training emphasizes forming strong relationships and giving positive attention, as well as setting limits and expectations to prevent either permissive or authoritarian parenting styles. This study reported significant success rates with most participating parents acquiring and retaining the target skills. Franks et al.'s (2013) project retroactively compared the 171 families who completed the training to a matched sample of at-risk biological families who received no particular extra support. Of the families who underwent the training, 114 had intact family outcomes, defined by either reunification (a child placed in foster care returned to their birth family) or the children never being removed from the family of origin. Conversely, only 56 of the control group families had intact family outcomes. Furthermore, the biological families who received the foster parent training had more cases closed six months out than the control group (Franks et al., 2013). 


\subsubsection{Foster Parent Attitudes}

Attitudes toward parenting roles and responsibilities, birth families, and motivations for fostering all impact foster family outcomes. Those parents who nurture, empathize with, and simply love the children placed in their homes are the most successful (Harden et al., 2008), as are caregivers who work thoughtfully and respectfully with foster care agencies and families of origin. Adults who seek the remuneration that comes with fostering or who are attempting to replace a lost child are more likely to feel stress and lack of attachment; meanwhile parents with previous experience fostering or those fostering to help children generally have a positive attitude toward fostering. Gillis-Arnold et al. (1998) established five major motivations for fostering: "childlessness, altruism and social conscience, identification with deprived children, wanting a larger family, and wanting to nurture children" (pg. 718). Motivation to foster anchored in the desire to help children, as opposed to receiving a stipend or replacing a lost child, leads to favorable outcomes for both the foster families and their children (Harden et al., 2008). Furthermore, while prospective adoptive parents are more likely than foster parent trainees to see fostering as "real" parenting, the latter group tends to better see the value of establishing relationships with the birth family, building toward reunification (Gillis-Arnold et al., 1998) or even collaborating and co-parenting.

Brown and Campbell (2007), similar to Linares et al. (2006), proposed investigating the efficacy of a collaboration between foster and biological families noting that the traditional models of parenting responsibilities need not be the only models considered. They suggested rather than pursuing an outcome in which children stay either with their birth parents or with a foster family that new family patterns in which both birth and foster parents play a role in promoting child well-being could be considered. Foster parents tend to believe that the characteristics necessary for a successful placement include addressing the child's basic security and safety needs, developing family connections and good relationships, and working well with foster agencies; furthermore, if both the foster family and the child show positive change and growth, foster parents are more likely to view the placement favorably. While the preponderance of literature on foster placement success makes presumptions about preferred outcomes, Brown and Campbell's (2007) study directly sought foster parents' voices, who both emphasized connections to birth families and focused on supporting children during transitions into and out of foster care. Cultivating positive working relationships with foster care agencies and biological parents generally creates a positive attitude toward fostering (Harden et al., 2008).

Harden et al. (2008) created a background questionnaire to understand the history of foster parents which did not include parents' previous experiences as foster youth; however, in the full Foster Parent Attitudes Questionnaire (FPAQ), these authors measured perspective-taking with items like "[b]ecause of my own experiences as a child, I understand what foster children are going through" (p. 886). This and additional research have indicated that positive foster parent characteristics include strengthening relationships beyond those with the children in the home (e.g., with the birth families, the wider community and social circles, and foster care agencies), understanding what is happening in the life of foster children, striving to connect with them, and realizing the impact foster parents can have on 
foster children's behavior (Brown and Campbell, 2007).

The stress of parenting, and especially the added stress of fostering, can create negative, authoritarian environments (Harden et al., 2008). It is important to note in one study, that foster parents' behaviors were not significantly connected to the amount of time a child was in their care indicating that knowing a child for an extended period of time did not make the foster parent either more or less likely to engage in positive or negative discipline (Vanderfaeillie et al., 2012). This finding suggests that if foster agencies focus predominantly on parenting stress, they will likely miss focusing on both child and parenting healthy behaviors.

Bunday et al. (2015) conducted a series of interviews with caregivers and noted that RF has potential limitations. Foster parents who had difficult childhood relationships were able to empathize with and positively parent foster children; however, unresolved personal and familial conflicts also led to difficulty with RF. In order for RF to work well, a caregiver has to understand the child and where they are coming from. This is far more difficult in a foster setting than in a biological home, given the family of origin's connections with the child from birth, shared history, and shared personality traits. Furthermore, fostering is challenging; these challenges, including externalizing behaviors that might trigger a caregiver's own past trauma, can make developing connections with the children difficult as well (Bunday et al., 2015).

The Adult-Adolescent Parenting Inventory (AAPI) is "used to assess high-risk parenting and child-rearing attitudes" (Gillis-Arnold et al., 1998), with four parental risk factors of note: having unrealistic expectations of the child, emphasizing physical punishment, confusing the parent-child roles, and failing to empathize with or understand the child's needs. Foster care agencies can use the AAPI and the Parent Development Interview (Bunday et al., 2015) to recruit and train foster families, promote higher RF, and, perhaps most importantly, provide support during foster care.

\subsection{Other Programs for At-Risk Families}

While research specific to positive outcomes for former foster youth in adulthood is scarce, and research on foster/birth families often omits youth voices and inputs, existing programs for at-risk youth and families offer some hope for positive development. The following programs address the needs of marginalized communities in ways that can promote youth voices and be adapted to support foster families:

Linares et al. (2006) specifically looked at evidence-based training programs that could be adapted for foster parents, given the lack of research and empirically-based foster training programs available. They noted that co-parenting is effective at improving outcomes for the children of divorced parents. Holland (2009) also noted that outcomes based on disruption and change are similar for children from divorced families and foster youth. They argue that one of the most critical factors to ensure successful foster placements and transitions that lessen foster drift is to listen to the youth themselves.

Perlman et al. (2012) investigated methods to encourage positive parenting skills in families 
who experienced homelessness. Homelessness is often studied primarily with a focus on negative outcomes with little attention paid to impoverished parents' specific strengths and needs. These authors found that positive parenting, regardless of circumstance, is marked by resiliency and warmth and that negative parenting is characterized by punitive discipline and a lack of support. Similar to foster families, homeless parents faced a cycle of considerable stress which was frequently compounded by youth externalizing behaviors. As a result, both parents and youth became increasingly more vulnerable to engaging in unhealthy behaviors. Specifically, the children struggled to negotiate the tribulations of poverty which was complicated with enduring authoritarian (harsh) or permissive (inconsistent or unconnected) parenting. Because of physical safety concerns and high rates of maltreatment of children in poverty, this population faces a disproportionately high risk for child removal from the family of origin (Perlman et al., 2012).

Parenting Through Change (PTC), a positive parenting training emphasizing acquiring skills like communication and involvement, showed strong outcomes for mothers going through a separation or divorce (Perlman et al., 2012); that change mirrors the disruptions children experience in both homeless shelters and foster care. When adapted for implementation in shelter settings, Family Care Curriculum (FCC), which focuses on helping parents build their RF skills, helped lower parental risk scores on the AAPI. Both PTC and FCC allowed shelter workers and others assisting families in need to move beyond triage to promoting growth and development for both parents and children (Perlman et al., 2012).

Levac (2013) initiated a program called Engage for Change to provide young mothers the opportunity to grow as leaders, demonstrate complex identities, and challenge existing systems. This intersectional approach was intentional and served a facilitating role in helping participants to see themselves and the others in the group as more than "just a young mother," as social norms tend to dictate. This program allowed young mothers to see how their "identities interact with social systems such as capitalism, sexism, and democracy, and how this affects their engagement as citizens and leaders" (pg. 426). Group participants identified each other's strengths and tapped them for maximum success showing outcomes that were generally positive, through reports of increased self-perceptions of leadership, agency, and ability to affect change with social safety net systems and policy makers in their city. Following program completion, they saw themselves as experts in areas like domestic violence and oppression who could consult with social workers on achieving effective solutions. These newly empowered perceptions, allowed program participants to directly confront the traditional notion that young mothers are victims or wrong-doers (Levac, 2013).

Svoboda et al. (2012) studied foster youth and pregnancy. Adolescents in foster care face a significant risk of pregnancy. In Maryland this rate is nearly three times higher among foster youth than youths who remained with their biological families. Young motherhood and foster care demographics are often similar, with high percentages of minority populations and incidence of childhood trauma. Svoboda et al. (2012) cited longitudinal studies like the Midwest Evaluation of the Adult Functioning of Former Foster Youth and the Massachusetts Task Force on Youth Aging-Out of Department of Social Services Care. The results tapped youth voices, who asked for the chance to receive more parenting training and to provide 
input and insight into their transitions. For these young mothers, the birth of a child encouraged them to put themselves in a position emotionally and financially to care for their children which could also safeguard them against the possibility of having their children removed from their care (Svoboda et al., 2012).

Campbell, Trzesniewski, Nathaniel, Enfield, and Erbstein (2013) evaluated the benefits of the state of California investing in positive youth development (PYD) programs, with the belief that PYD promotes skill building and helps youth achieve positive outcomes by developing meaningful abilities that lead to academic and emotional success. Their study of the Weikart Center for Youth Program Quality determined that programs for youth must provide safety, support, and engagement, and that they must allow for and encourage relationship-building. Program results indicated that adolescent participants experienced increased positive outcomes in intra- and interpersonal skills, civic engagement, empathy and compassion, sense of agency and purpose, academics, and decreased risky behaviors (Campbell et al., 2013).

\section{Theoretical Perspectives}

Parenting style, attachment, and family systems theories all address healthy youth development. Similarly, positive youth development theory and its related social justice youth development model offer advice about how to promote healthy development in the broader contexts of multiple family settings and social service agencies.

\subsection{Parenting/Family Theories}

Parenting style, attachment, and family systems all significantly impact youth development and often interact with each other. For example, parenting style may determine level of parent-child attachment and features of the family system (e.g. openness, communication, role organization) (Doinita and Maria, 2015). Each may also play a mediating or moderating role in impacting youth development depending on age and stage of development and context.

\subsubsection{Parenting style}

Parenting style research largely builds off Baumrind's (1991) work with the study of the balance between parental warmth/responsiveness and parental control/demandingness leading to four distinct climates of parent-child interaction: authoritarian, authoritative, permissive, and rejecting-neglecting. Parents high in both warmth and control tend to be more authoritative: they establish firm but flexible boundaries and expectations, communicate affectionately, and value the child's input. Authoritarian parents tend to be high in demandingness but low in responsiveness, with little flexibility or external displays of warmth. Permissive parents tend to be low in demandingness but high in warmth, providing few boundaries and little support or structure but a great deal of affection. Rejecting-neglecting parents tend to low in both warmth and control, essentially abandoning their parental responsibilities entirely (Baumrind, 1991; Welch, 2010). Authoritative parents have high expectations for their children, supported by warmth and understanding; these 
youth show positive outcomes like secure attachment and ability to form strong relationships outside of the family, positive self-identity, autonomy, and achievement (Baumrind, 1991; Welch, 2010). Authoritarian and permissive parents seek some of these outcomes, as well, albeit with different parenting styles and skill levels. Authoritarian parents, for example, do not typically provide the support and freedom youth need to determine their own individualized identities or the ability to forge new strengths (Baumrind, 1991), while children of permissive parents frequently demonstrate negative academic and social outcomes due to little accountability from the adults (Welch, 2010).

Boeldt et al. (2012) identified the strong connections between parenting styles and child externalizing behaviors. Positive parenting styles, typically aligned in Western societies with authoritative rather than authoritarian or permissive behaviors, can not only prevent children from "acting out" but can actually serve as a protective factor against future externalizing and internalizing behaviors. Boeldt et al. (2012) narrowed positive parenting into sensitivity, quality of instruction, warmth, and overall interaction; early applications of these behaviors strengthened the protective factors, and the positive effects could also be generated at later stages of development, as well.

\subsubsection{Attachment Theory}

Attachment to the child is the most significant factor in determining positive youth outcomes, as well as foster parent perceptions of success (Harden et al., 2008); furthermore, a strong attachment to one's children is considered to be the norm (Gillis-Arnold et al., 1998). Attachment is fostered through connections with a parent/caregiver from infancy, who is experienced as both available and responsive, which creates for the child an internalized framework for building trust, understanding, and engagement in later relationships (Doinita and Maria, 2015).

Inge Bretherton (1992) offers a concise history of John Bowlby, Mary Ainsworth, and the formulation of attachment theory. Bowlby initiated the theory when he observed that infants who had strong connections to their mothers, characterized by warmth and intimacy, seemed to demonstrate more positive development later. He focused on ethological features of attachment, like the instinct for an infant to get the attention of their caregiver to ensure they would be safe and have their needs met. Ainsworth built on this foundation by studying attachment and separation with infants and their mothers, noting the correlations between the parenting behaviors of the mothers and the reactions of their children to the mothers' presence, absence, and return. Securely attached children became upset when their mothers left but calmed quickly when they returned and resumed safe exploration of their space; other infants demonstrated separation anxiety, coined by Bowlby, and either struggled to console themselves after their mothers returned, remained indifferent to their mothers' presence or absence, or vacillated between the two reactions (Bretherton, 1992).

\subsubsection{Family systems theory}

Family systems theory argues that members of a family-children, parents, and extended members - operate not only as individuals but also in a complex series of relationships with 
each other and as a whole unit. Individuals develop through identifiable stages, but so does the family, marking milestones such as marriage, birth of children, and children leaving the home. The entire system includes connective functions like boundaries, organization, power, and communication, with many different styles of successful and dysfunctional families demonstrating various combinations of these characteristics (Bowen, 1966).

Family systems theory describes how families orient themselves around both individual and group dynamics. Much like parenting styles, families can operate as tightly closed units with strict rules and roles, as wide open groups with role diffusion and confusion, or with any degree of boundaries and rules in between (Bowen, 1966). Understanding the cultural background of a family can help reveal the emphasis placed on displays of affection, discipline, and relationships with those outside of the family; understanding the boundaries of the family can also explain the preferred style of communication, responses to change, openness to working with social service agencies, and consistency with rules.

\subsection{Youth/Community Theories}

Youth develop in the context of their broader community systems as well as their families, and their experiences in these communities can either support or control them. Youth need to be able to impact their communities as well to promote their own healthy development.

\subsubsection{Positive youth development}

Positive youth development (PYD) comprises diverse concepts connected by the belief in youth strengths and capacities. Rather than prevention, which seeks to stop the negative processes that lead to poor outcomes, or correction, which helps youth recover after problems arise, PYD takes an assets-based approach and examines both what youth are able to achieve and what they need to develop well (Benson, Galbraith, \& Espeland, 2006; Smith and Mammo, 2004).

Smith and Mammo (2004) synthesized PYD concepts into one multi-faceted framework: youth who are viewed as partners rather than problems, supported by their communities and adults, and given opportunities to learn, participate, and grow will have the best outcomes. Furthermore, promoting positive development serves preventative and protective functions while simultaneously building youth assets.

PYD notes the importance of adults in support roles, rather than in positions of authority. This includes establishing clear, open communication that encourages youth voices, as well as efforts to move youth toward empowerment and initiative themselves (Clary and Rhodes, 2006). Adults seeking to serve youth through PYD can utilize the Search Institute's 40 internal and external developmental assets as an instructive framework, helping to establish support networks within families, neighborhoods, and schools; to create boundaries; to build positive relationships with adults and peers; to strengthen self-identity and values; and to set high internal and external expectations (Benson, Galbraith, \& Espeland, 2006; Clary and Rhodes, 2006). 


\subsubsection{Social Justice Youth Development}

Ginwright and Cammarota (2002) developed the framework of social justice youth development (SJYD) to explain how youth can be empowered through PYD to better themselves and their communities. Much like physical or emotional toxins, which could constitute abuse or neglect and lead to a child's removal from their family of origin, Ginwright and Cammarota (2002) identified social toxins: violence, poverty, and other systemic/social/economic ills that negatively impact youth, especially in impoverished communities. These social toxins can manifest as both internalizing and externalizing behaviors in youth. Furthermore, these authors define risk for negative youth outcomes as comprising not only these externalizing behaviors but also the environment in which they develop, which "might include unsafe neighborhoods, lack of health care, racist school practices, lack of livable wage-earning jobs, and few productive after-school opportunities. These conditions ultimately threaten the overall well-being of neighborhoods and communities" (Ginwright \& Cammarota, 2002, p. 86). At-risk youth are not simply at risk of committing destructive acts in the future - they are at risk because of the many factors weighing down on them from personal, social, and systemic influences.

The answer to this conundrum lies in critical consciousness plus social action. SJYD argues that youth can and should be seen as active participants in dismantling the structures of oppression and control, and looks at how youth address their relationships with power as well as those persons, groups, or systems who wield it. Critical consciousness in SJYD comprises three levels of awareness: self (identity, how oppression and privilege operate in their lives); social (how the youth interact with their immediate surroundings/communities); and global (how youth engage/empathize with those struggling around the world). Understanding how these different levels of social toxicity impact youth becomes more meaningful when they have the opportunity to access their power to address the injustices (Ginwright \& Cammarota, 2002).

Both youths and adults see positive outcomes from SJYD work. Youth have new perspectives on the world and see themselves as more powerful and capable; they also demonstrate actual emotional and physical healing. Adults, meanwhile, understand that youth are not simply individuals but exist as individuals in community and social contexts, making their work more effective as well (Ginwright \& Cammarota, 2002). Additionally, a SJYD approach seeks to blur the line between the youth and mentor to establish collaboration, create relationships with youths on more equal grounds, and move youths to real action. Adults and youth frequently operate on uneven levels, exacerbated by views of young people as either innocents in need of protection or, in the case of at-risk youth, dangerous actors who make poor choices (Tilton, 2013). Recognizing young people as intersectional agents in their lives and communities frees adults to acknowledge the youths' skills and positive attributes while helping address their needs. 


\section{Synthesis of Theory and Research}

Crum (2009) suggests that foster care agencies should evaluate their training and support programs to ensure they are meeting the real, demonstrated parenting needs of the foster families and that foster child behavior problems made attachment with foster families more difficult. Children are socialized in their biological families, and they come to foster parents with a set of learned behaviors and communication skills that can perpetuate negative interactions; foster families can either reinforce or mitigate these maladaptive patterns through their parenting approaches.

Fuentes et al. (2014) attempted to fill a gap in the research studying how foster parenting impacts youth behaviors. They found that parenting style and child behaviors seem to be bidirectionally connected: when foster families use positive parenting techniques, children's poor behaviors decrease, and when children's behavior is less disruptive, foster parents are more likely to respond positively. Neither the children's nor the foster family's personal characteristics or history, including length of placement, impacted the children's behavior, indicating that the child behaviors and parenting styles are connected. Specifically, according to these authors, "a large proportion of the externalizing behaviour problems shown by these children could be explained by the presence of criticism and rejection on the part of foster caregivers" (pg. 709). Both authoritarian and permissive parenting styles were found to lead to poor connections. A foster child's internalized behaviors can result in a foster parent's poor esteem about their abilities as a parent/foster caregiver, which in turn could lead to the use of either of the styles related to poor connections. Meanwhile, authoritative parenting (e.g. characterized by warmth, attachment, caring, and empathy) promoted unconditional love and care from the foster parents; as a result, youth developed better connections with their foster families and were more likely to make progress toward positive outcome goals (Fuentes et al., 2014).

Training biological and foster families together builds relationships, creates consistency for the children, and is an effective use of resources (Linares et al., 2006). Former foster youth understand the necessity to build relationships with birth families and communities (Brown \& Campbell, 2007). Despite these important relationship connections, attachment theory has not been adequately employed either to explain foster child internalizing or externalizing behaviors or to connect those behaviors to previous relationships (Bunday et al., 2015).

Even though the children come with their biological makeup, both the biological and the foster family relationships can shape the youths' development (Vanderfaeillie et al., 2012). Children learn from the adults around them, and while their initial coping strategies are modeled after their biological parents, they can relearn healthy attachment and relationship skills from foster families. Foster parents' use of negative and/or inconsistent discipline impacted their ability to form attachments to their foster children, and the children's ability to form attachments with them (Vanderfaeillie et al., 2012). Meanwhile, support from foster parents can encourage development of the positive assets that allow their foster youth to form healthy attachments in the foster family, the birth family if possible, and the school and community (Clary \& Rhodes, 2006). 


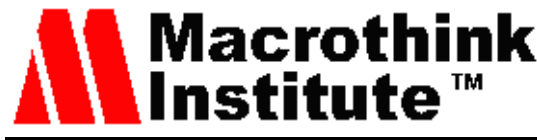

Three components of family systems theory directly apply to a foster care setting: the distribution of power, the responses to change, and communication. Birth families that struggle with any of these, especially in combination with each other, face the risk of sliding into dysfunction or maltreatment of the children. Authoritarian parents who value strict role ordering could lash out at their children when they feel disrespected or when they are facing external stress; combining this with poor communication skills would also inhibit how the members of the family were able to work through their problems as a unit. Furthermore, if a family negatively responds to change, whether manifested as the usual developmental transitions of the individuals or the family as a whole, or as sudden shocks to the system, it can exhibit through maltreatment. All of these would potentially lead to the removal of children from the family of origin, which adds another stressor to the family members and the family. Furthermore, permissive families who had come to rely on a child to provide emotional support and stability could destabilize when that person was removed from the home.

In addition to the strain for a biological family, a foster family must be ready, often at just a few hours' notice, to bring a new child or children into their system. For this to work, the foster family's system must be open enough to truly welcome the new additions in healthy relationships and roles, but have adequate boundaries to provide security for all members. Foster parents potentially need to help their biological children negotiate the new sibling relationships and understand the connections each foster child will have with the parents. Depending on the age and developmental level of both foster and biological children, children might: 1) enter the foster home at a transitional moment the foster parents were not prepared to address, 2) redirect the parents back to a stage they thought they had negotiated successfully, or 3 ) force them to straddle multiple stages at once.

Finally, all research indicates that as long as the children are able to remain safe, youths attain the best outcomes when their foster and birth families have good relationships (Brown \& Campbell, 2007; Crum, 2010; Fuentes et al., 2014; Holland, 2009; Linares et al., 2006). New research hints that collaborative or even co-parenting situations between the two families could be beneficial, as well (Brown \& Campbell, 2007; Linares et al., 2006). This could require the foster and birth families to reorganize as one extended unit, recognizing and mitigating potential conflicts with power distribution, assignment of roles, and communication.

The most successful outcomes for both foster youth and their foster caregivers all focus on recognizing and strengthening assets for both groups. PYD emphasizes the necessity of supportive adults who provide youth the opportunities for challenge and growth while ensuring their emotional, physical, and psychological safety. Foster parents who hone their own reflective functioning can better understand where youths' emotions and behaviors derive, better respond in supportive rather than punitive or reactive ways, and more fully promote the youths' attachment. This, in turn, leads to more positive outcomes that last into adulthood, giving former foster youth an array of assets like empathy, compassion, and interpersonal relationship skills that would ensure they, in turn, could become strong foster parents themselves. 
Ein-Dor and Hirschberger (2016) propose a new understanding of attachment theory that would seem to serve foster youth and families well, especially under a combined family systems/PYD approach. They argue that individuals with attachment anxiety or attachment avoidance - that is, those who have struggled to form secure, positive attachments - may have developed advantages that those with secure attachments lack. Furthermore, groups comprising individuals with both secure and anxious attachments may benefit from the wider array of assets from which to draw (Ein-Dor \& Hirschberger, 2016). Anxiously attached individuals were more attuned to danger and better equipped to warn others clearly and quickly, a protective feature; they also were more capable of interpreting social cues than their securely attached counterparts. Attachment avoidant individuals tended to struggle with collaboration and be more concerned with their own safety in dangerous situations, but this also led to action that helped others find safety; they were also able to identify and express their own needs without concern (Ein-Dor \& Hirschberger, 2016). To promote healthy self-esteem and stronger relationships with their foster children, foster families can look at the assets of the non-securely attached youth in their care. Heeding the words and actions of these children can contribute to overall group strength for the family, allow the parents to meet each youth at their current stage of development, and provide a path forward toward better attachment and more positive outcomes overall.

\section{Discussion}

Boeldt et al. (2012) note that the protective benefits of positive parenting can be generated well after infancy and toddlerhood. This has been used to support the concept of training biological parents to have better parenting skills, as well as training foster families to best serve the needs of the children in their care. Therefore, foster children are not "beyond hope" or doomed to poor outcomes in adulthood; instead, intentional efforts to provide foster youth with the environments they both need and want can provide those same protective factors, even later in adolescence. These protective factors can help former foster youth take their empathy for and understanding of foster children's difficult situations, as well as their knowledge of both positive and negative parenting skills, and become effective foster parents themselves.

Fixating on a "former foster youth" label as the sole trait marking a parent, especially with the accompanying deficit outcomes, will cause interested stakeholders to fail to embrace the positive outcomes foster children acquire as a result of their experience. These youths enter adulthood with compassion, problem-solving, and resiliency; they can understand the emotions and reactions of children entering foster care better than the most well-meaning foster parents and social workers. Levac (2013) comments, "Public discussions and images of young mothers are instead rife with negativity, and treat young mothers and their children as problems that require fixing. This deficit-based understanding ignores young mothers' strengths, contributions to society, and leadership capacities, and fails to consider their contribution to a community's collective capacity" (p. 424); the same criticism can be levied against many adults who simply brush off the potential and actual contributions of youth, 
especially those in high-risk or marginalized situations. Parents who adopt children are more likely to have gone through painful experiences such as loss of a child, infertility, or childhood trauma than other parents (Bunday et al., 2015); if this is already the experience of adoptive parents, then harnessing the positive skills of FFY through training and support can help channel this loss into successful foster parenting for future children.

One major question for both foster care agencies and families is how can they apply PYD techniques to improve outcomes in their youth? Children, especially and powerfully exemplified by those in foster care, want to have their voices heard. However, this is a difficult and occasionally scary process, one which requires guidance and support from adults in their lives. PYD programs allow caregivers and social workers to facilitate growth by fostering leadership, relationship-building, and communication skills, by positioning youth as agents in their community, and by amplifying youths' voices in the process of foster placement, transitions, and life outside the foster setting. Furthermore, SJYD work can help foster children understand the complex social institutions that lead to maltreatment and family disruption, including cycles of poverty and violence. This critical consciousness could alleviate internalizing behaviors by helping youth realize they are not the cause of their removal from their homes; it could also serve to facilitate better relationships with the families of origin by reminding the youth that their parents are operating in community settings that either support or oppress struggling groups.

Arguably the most potent aspect of SJYD is the action within the community: it is not enough to understand the problems, but rather youth themselves should be empowered to create solutions to address these issues meaningfully. Foster youth are in a unique position to see the effects of multiple parenting styles, as well as the institutions that step in when maltreatment occurs. These children are in a unique position to act as agents in the community to effect meaningful change. They can also work through the system to help improve outcomes for future generations of children in need of those same services. This raises the question of just how far foster youth can and should be involved. If young people know what they want and need to feel successful, supported, and happy, and they know all parts of the system, what can be done to involve them in case planning, placements, and transitions? Can foster youth participate in the foster/biological parent trainings, giving them insights into family communication skills and efforts their parents are making? How can their experiences be leveraged as expertise to make the foster care system better for the young people themselves?

Some limitations need to be examined with these questions, but care must be taken to ensure that the perceived limitations that have prevented exploration in this area previously are not conflated with real concerns that would need to be addressed. Foster care agencies and families serve youth on a broad spectrum of ages, abilities, and emotional/cognitive levels, and not every child would be in a position to successfully advocate for themselves. However, this should not stand in the way of those youth, who can and are willing to address their needs and those of the broader system, being actively sought and engaged in the process of bettering the system. 


\section{Conclusion}

This article demonstrated that foster care is stressful for youth, foster parents, biological families, and wider communities in a variety of ways. These stressors can lead to negative outcomes, but training in positive parenting skills and positive youth development can improve outcomes for each of these groups. While many foster youth will transition to adulthood without the skills needed to become successful foster parents themselves, foster children can have the necessary empathy and understanding to make important connections with others in foster care. With evidenced-based training programs, this empathy can be translated into meaningful support as a foster parent. Much more research is needed to understand the outcomes for former foster youth in adulthood, particularly with regard to their parenting styles, skills, and deficits, as well as the potential positive outcomes for children that can be gained by moving through the foster care system. Parenting styles, attachment, and family systems theories can drive research into how foster youth form positive connections with both families of origin and families of placement, as well as how each family can best meet their collective needs and the needs of their individual members. Positive youth development and its offshoot social justice youth development can inform research methods, especially in seeking participants who are current or former foster youth; PYD and SJYD also highlight the assets that former foster youth develop and can instruct researchers in creating studies examining how these assets are utilized in adulthood.

\section{Declaration of Conflicting Interest}

The authors declare that there is no conflict of interest.

\section{References}

Ahmed, K., Windsor, L., \& Scott, S. (2015). In their own words: Abused children's perceptions of care provided by their birth parents and foster caregivers. Adoption \& Fostering, 39(1), 21-37. https://doi.org/10.1177/0308575914565068

Baumrind, D. (1991). The influence of parenting style on adolescent competence and substance use. The Journal of Early Adolescence, 11(1), 56-95. https://doi.org/10.1177/0272431691111004.

Benson, P.L., Galbraith, J., \& Espeland, P. (2006). What kids need to succeed. Minneapolis. MN: Free Spirit.

Bigner, J.J. (2010). Parent-child relations: An introduction to parenting ( $8^{\text {th }}$ ed.). Upper Saddle River, NJ: Merrill.

Boeldt, D.L., Rhee, S.H., DiLalla, L.F., Mullineaux, P.Y., Schulz-Heik, R.J., Corley, R.P., Young, S.E., \& Hewitt, J.K. (2012). The association between positive parenting and externalizing behavior. Infant and Child Development, 21, 85-106. https://doi.org/10.1002/icd.764. 
Bowen, M. (1966). The use of family theory in clinical practice. Comprehensive Psychiatry, 7(5), 345-374. https://doi.org/10.1016/S0010-440X(66)80065-2

Bretherton, I. (1992). The origins of attachment theory: John Bowlby and Mary Ainsworth. Developmental Psychology, 28(5), 759-775. https://doi.org/10.1037/0012-1649.28.5.759.

Brown, J.D., \& Campbell, M. (2007). Foster parent perceptions of placement success. Children and Youth Services Review, 29, 1010-1020. https://doi.org/10.1016/j.childyouth.2007.02.002.

Bunday, L., Dallos, R., Morgan, K., \& McKenzie, R. (2015). Foster caregivers' reflective understandings of parenting looked after children: An exploratory study. Adoption \& Fostering, 39(2), 145-158. https://doi.org/10.1177/0308575915588730.

Campbell, D., Trzesniewski, K., Nathaniel, K.C., Enfield, R.P., \& Erbstein, N. (2013). Positive youth development merits state investment. California Agriculture, 67(01)(38). https://doi.org/10.3733/ca.v067n01p38.

Clary, E.G., \& Rhodes, J.E. (2006). Mobilizing adults for positive youth development: Strategies for closing the gap between beliefs and behaviors. The Search Institute Series on Developmentally Attentive Communities and Society, PL Benson (Series Ed.). Minneapolis, MN: Springer. https://doi.org/10.1007/0-387-29340-X.

Crum, W. (2010). Foster parent parenting characteristics that lead to increased placement stability or disruption. Children and Youth Services Review, 32, 185-190. https://doi.org/10.1016/j.childyouth.2009.08.022.

Doinita, N.E., \& Maria, N.D. (2015). Attachment and parenting styles. Procedia-Social and Behavioral Sciences, 20, 199-204. International Conference Education and Psychology Challenges-Teachers for the Knowledge Society, (3rd Ed.), EPC-TKS 2015. https://doi.org/10.1016/j.sbspro.2015.08.282.

Ein-Dor, T., \& Hirschberger, G. (2016). Rethinking attachment theory: From a theory of relationships to a theory of individual and group survival. Current Directions in Psychological Science, 25(4), 223-227. https://doi.org/10.1177/0963721416650684.

Franks, S.B., Mata, F.C., Wofford, E., Briggs, A.M., LeBlanc, L.A., Carr, J.E., \& Lazarte, A.A. (2013). The effects of behavioral parent training on placement outcomes of biological families in a state child welfare system. Research on Social Work Practice, 23(4), 377-382. https://doi.org/10.1177/1049731513492006.

Fuentes, M.J., Salas, M.D., Bernedo, I.M., \& Garcia-Martin, M.A. (2014). Impact of the parenting style of foster parents on the behaviour problems of foster children. Childcare, health and development, 41(5), 704-711. https://doi.org/10.1111/cch.12215.

Gillis-Arnold, R., Crase, S.J., Stockdale, D.F., \& Shelley II, M.C. (1998). Parenting attitudes, foster parenting attitudes, and motivations of adoptive and nonadoptive foster parent trainees. Children and Youth Services Review, 20(8), 715-732. 
https://doi.org/10.1016/S0190-7409(98)00033-4.

Ginwright, S., \& Cammarota, J. (2002). New terrain in youth development: The promise of a social justice approach. Social Justice, 29(4), 82-95.

Harden, B.J., Meisch, A.D., Vick, J.E., \& Pandohie-Johnson, L. (2008). Measuring parenting among foster families: The development of the Foster Parent Attitudes Questionnaire (FPAQ). Children and Youth Services Review, 20(8), 879-892. https://doi.org/10.1016/j.childyouth.2007.12.015.

Holland, D.D. (2009). Families of origin, foster care experience, and the transition to adulthood. Juvenile and Family Court Journal 60, 2(Spring), 69-85. https://doi.org/10.1111/j.1755-6988.2009.01027.x.

Levac, L. (2013). 'Is this for real?' Participatory research, intersectionality, and the development of leader and collective efficacy with young mothers. Action Research, 11(4), 423-441. https://doi.org/10.1177/1476750313508327.

Linares, L.O., Montalto, D., Li, M., \& Oza, V.S. (2006). A promising parenting intervention in foster care. Journal of Counseling and Clinical Psychology, 74(1), 32-41. https://doi.org/10.1037/0022-006X.74.1.32.

Perlman, S., Cowan, B., Gewirtz, A., Haskett, M., \& Stokes, L. (2012). Promoting positive parenting in the context of homelessness. American Journal of Orthopsychiatry, 82(3), 402-412. https://doi.org/10.1111/j.1939-0025.2012.01158.x.

Small, S., \& Memmo, M. (2004). Contemporary models of youth development and problem prevention: Toward an integration of terms, concepts, and models. Family Relations, 53(1), 3-11. https://doi.org/10.1111/j.1741-3729.2004.00002.x.

Solomon, D.T., Niec, L.N., \& Schoonover, C.E. (2017). The impact of foster parent training on parenting skills and child disruptive behavior: A meta-analysis. Child Maltreatment, 22(1), 3-13. https://doi.org/10.1177/1077559516679514.

Svoboda, D.V., Shaw, T.V., Barth, R.P., \& Bright, C.L. (2012). Pregnancy and parenting among youth in foster care: A review. Children and Youth Services Review, 34(5), 867-875. https://doi.org/10.1016/j.childyouth.2012.01.023.

Tilton, J. (2013). Rethinking youth voice and institutional power: Reflections from inside a service learning partnership in a California juvenile hall. Children and Youth Services Review, 35(8), 1189-1196. https://doi.org/10.1016/j.childyouth.2013.02.015.

Vanderfaeillie, J., Van Holen, F., Trogh, L., \& Andries, C. (2012). The impact of foster children's behavioural problems on Flemish foster mothers' parenting behavior. Child \& Family Social Work, 17, 34-42. https://doi.org/10.1111/j.1365-2206.2011.00770.x

Welch, K.J. (2010). Family life now (2nd ed.). Boston, MA: Allyn \& Bacon. 


\section{Copyright Disclaimer}

Copyright for this article is retained by the author(s), with first publication rights granted to the journal.

This is an open-access article distributed under the terms and conditions of the Creative Commons Attribution license (http://creativecommons.org/licenses/by/3.0/). 